disclosed absence of microperoxisomes. In the control samples numerous peroxisomes $(0.6 \mu \mathrm{m})$ were seen together with a few small dense-staining microperoxisomes scattered in the cytoplasm. The latter particles were characterized by a dense matrix surrounded by a lucent or "empty" halo. In the samples from the patients there were autophagic vacuoles in various stages of development and abundant residual bodies. Compared to the control samples, the Golgi complex was difficult to recognize, although present.

Clofibrate treatment did not result in occurrence of detectable peroxisomes or microperoxisomes (Fig. 1b). Enzyme histochemistry substantiated this conclusion (Fig. $2 a$ ). This absence of peroxisomes was not due to postmortem artefacts, since in liver tissues from kidney transplant donors taken $1 \mathrm{~h}$ after circulatory arrest, peroxisomes were easily identified (Fig. $2 b$ ). However, the treatment seemed to cause some enlargement of occasional mitochondria, vesiculation of their cristae, and scattered lipid inclusion bodies in the cytoplasm.

Our failure to induce peroxisomes in the two Zellweger patients is in accordance with the hypothesis that the protein missing in this disease is absolutely essential for the formation of peroxisomes. It cannot be completely excluded, however, that an earlier postnatal treatment would have had an effect.

\section{REFERENCES}

1. Bowen P, Lee CSN, Zellweger H, Lindenberg R 1961 A familial syndrome of multiple congenital defects. Bull Johns Hopkins Hosp 114:402-414
2. Goldfischer S, Moore CL, Johnson AB, Spiro AJ, Valsamis MP, Wisniewski HK, Ritch RH, Norton WT, Rapin I, Gartner LM 1973 Peroxisomal and mitochondrial defects in the cerebro-hepato-renal syndrome. Science 182:62-64

3. Borst P 1983 Animal peroxisomes, lipid biosynthesis and the Zellweger syndrome. Trends Biochem Sci:269-272

4. Lazarow $\mathrm{PB}$, DeDuve C $1976 \mathrm{~A}$ fatty acid-CoA oxidizing system in rat liver peroxisomes, enhancement by clofibrate, a hypolipidemic drug. Proc Natl Sci USA 73:2043-2046

5. Chatterjee B, Demyan WF, Lalwani ND, Reddy JK, Roy AK 1983 Reversible alteration of hepatic messenger RNA-species for peroxisomal and nonperoxisomal proteins induced by the hypolipidemic drug WY-14, 643. Biochem J 214:879-883

6. Miura S, Mori M, Takiguchi M, Tatibana M, Furuta Muazawa S, Hashimoto T 1984 Biosynthesis and intracellular transport of enzymes of peroxisomal $\beta$-oxidation. J Biol Chem 259:6397-6402

7. Hanson RF, VanLeeuwen PS, Williams GC, Grabowski G, Sharp HL 1978 Defects of bile acid synthesis in Zellweger's syndrome. Science 203:11071108

8. Parmentier GG, Janssen GA, Eggermont EA, Eyssen HJ $1979 \mathrm{C}_{27}$-Bile acids in infants with coprostanic acidemia and occurrence of a $3 \alpha, 7 \alpha, 12 \alpha$ trihydroxy-5 $\beta-C_{29}$ dicarboxylic bile acid as a major component in their serum. Eur J Biochem 102:173

9. Björkhem I, Sisfontes L, Boström B, Kase B, Hagenfeldt L, Blomstrand R 1984 Possibility of prenatal diagnosis of the Zellweger syndrome. Lancet 1:1234-1235

10. Brown I, McAdams AJ, Cummins JW, Konkol R, Sing I, Moser AB, Moser HW 1982 Cerebro-hepato-renal (Zellweger) syndrome and neonatal adrenoleukodystrophy: Similarities in phenotype and accumulation of very long chain fatty acids. Gen Clin Johns Hopkins Hosp 151:344-36

11. Nemeth A, Strandvik B, Glaumann H 1983 Alpha-1-antitrypsin deficiency and juvenile liver disease. Virchows Arch Cell Pathol 44:15-33

12. Novikoff AB, Novikoff PM, Davis C, Nelson Q 1972 Studies on microperoxisomes. A cytochemical method for light- and electron microscopy. J Histochem Cytochem 20:1006-1023

\title{
Growth and Development of Pediatric Research ${ }^{1}$
}

\author{
E. RICHARD STIEHM
}

Department of Pediatrics, UCLA School of Medicine, Los Angeles, California 90024

\begin{abstract}
Pediatric research may be entering a period of failure to thrive. This is despite impressive scientific achievements, significant financial benefits, intriguing unanswered questions and a rewarding life for the pediatric researcher. Many of the difficulties are financial and situational, including small departments and divisions, few pediatric research mentors, impecunious pediatric hospitals and services, ethical constraints on pediatric research and competing responsibilities. Grants to pediatric departments represent about $3 \%$ of the total NIH research project support. The two largest federal programs supporting $\mathrm{Pe}-$ diatric Research are the Clinical Research Center (CRC) program $(20 \%$ of an $\$ 28,000,000 / y r$ budget) and the $\mathrm{Na}$ tional Institutes of Child Health and Human Development $(17 \%$ of a $\$ 123,000,000 / y r$ budget $)$. There are 75 CRCs of which 60 admit children; 10 CRCs are in children's hospital and 6 other CRCs have a clear pediatric focus. Pediatric Departments receive $3 \%$ of $\mathrm{NIH}$ funds; this represents
\end{abstract}

Reprint requests E. Richard Stiehm, M.D., Professor of Pediatrics, UCLA School of Medicine, Los Angeles, CA 90024.

Presidential Address, Western Society of Pediatric Research Carmel, CA February 1984
$10 \%$ of funds to clinical departments. By contrast medicine departments receive $17 \%$ of NIH funds ( $47 \%$ of funds to clinical departments). NIH research support to pediatrics $(\$ 82,000,000 / y r)$ is centered in a few large departments; 14 pediatric departments receive 343 of the 572 NIH grants $(60 \%)$. By contrast, 66 of 120 pediatric departments have no (45) or 1 (21) NIH grants. Obstacles are identified and suggestions are offered for future (students and residents), beginning (fellows and assistant professors), established (associate and full professors) and women pediatric researchers. (Pediatr Res 19:593-598)

Pediatric research can use all the help it can get. Despite monumental scientific advances and proven cost benefits (eg, elimination of poliomyelitis), pediatric research (and other medical research), has undergone a growth arrest (1). If we are not vigilant, pediatric research can begin a period of failure to thrive. This essay addresses some ways to maintain its growth and development. I shall point out some advantages and disadvantages of pediatric research, discuss some financial aspects of 
Table 1. Advantages and disadvantages of pediatric research

Advantages
1. Close association with pediatrics, children, parents
2. Families are usually available
3. Large impact on health care
4. Certain fields are readily studied
a. Immunodeficiency
b. Perinatology
c. Dysmorphology
d. Behavior and development
e. Inborn errors of metabolism, genetics
f. Vaccine trials
5. Less competitive field-more appreciated
6. Alternative of pediatric practice is less attractive
a. Job dissatisfaction high
b. Financial rewards less
Disadvantages
1. Less research opportunities
a. Fewer mentors, positions, research laboratories, research-ori-
ented departments
b. Smaller departments, divisions-critical mass lacking
2. Less research funding
a. Few wealthy donors, foundations
b. Pediatric hospitals are underfunded
3. More ethical constraints on research
4. Reluctance of parents to have children used for research
5. Biological samples are hard to obtain, small in size
6. Controls are hard to obtain

pediatric research, and offer some suggestions for new and old pediatric researchers of both sexes.

\section{ADVANTAGES AND DISADVANTAGES IN PEDIATRIC RESEARCH}

Pediatric research has several unique aspects that give it a special attractiveness (Table 1). For those who chose medicine because of the contact with children and families, pediatric research offers ample opportunity for close interaction. Indeed in pediatric clinical research, close contact with the child and his/her parents is essential, and often is more intense and prolonged than in pediatric practice. Further, pediatric research provides an opportunity to give specialized care to a select group of patients. These make pediatric research an attractive alternative to pediatric practice with its demanding schedule, relatively low pay, and significant degree of physician dissatisfaction (2).

Pediatric research covers an enormous spectrum from molecular biology to infant development. Unique areas encompassed by pediatric research include developmental biology, perinatology, child development, and dysmorphology. Even in broad fields such as immunology, infectious diseases, and genetics, unique pediatric problems emerge, eg, the study of immunodeficiency, the testing of vaccines, and the detection, delineation, and correction of inborn errors of metabolism.

Pediatric research has an excellent cost-benefit ratio $(3,4)$. The increased survival of tiny premature infants, the formulation of oral rehydration solutions for diarrhea, the development of new vaccines, and the institution of neonatal screening for phenylketonuria and hypothyroidism are major advances that are of direct benefit to children. Yet many unsolved problems remain, such as the cause and treatment of mental retardation, the cure of childhood cancer, and the prevention of premature births. These will provide a wealth of challenges to the new cadre of pediatric investigators.

Good pediatric investigators are scarce. Most US medical schools do not have a significant pediatric research program. But where there is underdevelopment, there is opportunity. Productive pediatric investigators are highly appreciated.

The disadvantages to a career in pediatric research also are shown in Table 1. Small pediatric departments, few pediatric hospitals (in contrast to the network of VA and military hospi-
Table 2. NIH research project support to US medical schools$1983^{*}$

\begin{tabular}{lcc} 
& No. of grants & Dollars \\
\hline Basic sciences & 8324 & $909,000,000$ \\
Clinical sciences & 4378 & $620,000,000$ \\
(Pediatrics) & $(390)$ & $(53,000,000)$ \\
Other sciences & 1688 & $174,000,000$ \\
& & $\$ 1,703,000,000$ \\
\hline
\end{tabular}

* Pediatric departments receive $2.7 \%$ of the grants and $3.1 \%$ of the funds for all NIH grants to medical schools. Pediatric departments receive $8.9 \%$ of the grants and $11.7 \%$ of the funds of all NIH grants to medical school clinical departments.

tals), and the deficit finances of most pediatric services leads to a deemphasis on research. This means few mentors and few research programs. This has resulted in a number of pediatric investigators seeking research training outside of pediatric departments. Insufficient time for research plagues many (most) pediatric researchers. Pediatric departments tend to be small, the teaching and clinical loads are large, and the time required to supplement faculty income by part-time clinical duties is large because of the nature of pediatric practice.

Several other problems of pediatric research include the ethical limitations of experimental studies on minors, the reluctance of parents to permit the use of their children for research subjects, and the difficulty in obtaining even small quantities of blood from pediatric subjects. Obtaining controls, particularly agematched well children, is extremely difficult. Parents often are reluctant to allow "experimentation" on their child, although they will participate themselves.

\section{PEDIATRIC RESEARCH FUNDING}

Funding for pediatric research remains an endless quest. Endowment funds and private donations provide significant pediatric research support only in a handful of institutions. Some foundations (eg, The National Foundation, the Cystic Fibrosis Foundation) provide pediatric research support in specialized pediatric fields; this is dwarfed when compared to the nonpediatric research funds of the American Heart Association or the American Cancer Society. Patient donations also are limited, since pediatric patients and their parents usually are not wealthy. Thus, most pediatric research support comes from the Federal government, particularly the $\mathrm{NIH}^{2}{ }^{2}$

Two NIH agencies are notable for their absolute and relative support of pediatric research. The first is the CRC program of the Division of Research Resources. This program supports clinical research at 75 Centers throughout the USA, primarily at teaching hospitals. A generous portion $(30 \%)$ of their annual budget $(\$ 83,000,000)$ goes to pediatric research. In $1982,6,562$ of 26,743 total admissions (25\%) to these centers were infants and children. Further, 30 of the 100 CRC trainees have been pediatricians (the clinical associate physician program). Sixty of the 75 research centers admit children, 10 of the CRCs are in pediatric hospitals, and six other CRCs have a clear pediatric focus.

The second agency supporting pediatric research is the National Institute of Child Health and Human Development. In addition, several other NIH institutes provide significant pediatric research support, even though it is not a major focus.

Table 2 shows the 1983 pediatric and total research project support (individual research grants and program project grants, but not training grants or institutional grants) to all US medical schools. Although this excludes research performed at some large hospitals including Children's and VA Hospitals, the relative degree of support can be estimated from these figures. Pediatric Departments received $\$ 53,000,000$, which represents 390 of the

\footnotetext{
${ }^{2}$ Abbreviations: NIH, National Institutes of Health; CRC, Clinical Research Center.
} 
Table 3. NIH research project support to academic clinical departments-1983

\begin{tabular}{lrrrr}
\hline & \multicolumn{1}{c}{$n$} & $\%^{*}$ & \multicolumn{1}{c}{ Dollars } & $\%^{*}$ \\
\hline Anesthesiology & 69 & 0.5 & $7,900,000$ & 0.5 \\
Dermatology & 76 & 0.5 & $9,050,000$ & 0.5 \\
Family Practice & 22 & 0.2 & $4,380,000$ & 0.3 \\
Medicine & 2,040 & 14.2 & $291,200,000$ & 17.1 \\
Neurology & 190 & 1.3 & $28,800,000$ & 1.7 \\
Obstetrics and gyne- & 169 & 1.2 & $19,270,000$ & 1.1 \\
$\quad$ cology & & & & \\
Ophthalmology & 332 & 2.3 & $38,620,000$ & 2.3 \\
Orthopedic surgery & 49 & 0.3 & $4,840,000$ & 0.3 \\
Other clinical sciences & 8 & 0.1 & $1,220,000$ & 0.1 \\
Otolaryngology & 48 & 0.3 & $8,020,000$ & 0.5 \\
Pediatrics & 390 & 2.7 & $52,690,000$ & 3.1 \\
Physical medicine and & 6 & 0.06 & 52,000 & 0.01 \\
$\quad$ rehabilitation & & & & \\
Psychiatry & 111 & 0.8 & $12,110,000$ & 0.7 \\
Public Health and & 223 & 1.6 & $40,300,000$ & 2.4 \\
$\quad$ preventive medicine & & & & \\
Radiology & 261 & 1.8 & $44,440,000$ & 2.6 \\
Surgery & 384 & 2.7 & $56,000,000$ & 3.3 \\
$\quad$ Total & & & & \\
\hline
\end{tabular}

* Percentage of total NIH project support.

Table 4. Individual NIH institutes research project support to pediatric departments-1983

\begin{tabular}{|c|c|c|c|c|}
\hline Institute & $\begin{array}{c}\text { Pediatrics } \\
\text { grants/total } \\
\text { grants }\end{array}$ & $\%$ & $\begin{array}{c}\text { Support in } \\
\text { dollars }\end{array}$ & $\%$ \\
\hline Aging & $3 / 348$ & 0.9 & 383,000 & 0.9 \\
\hline Allergy & $57 / 1256$ & 4.5 & $4,157,000$ & 4.9 \\
\hline Arthritis & $65 / 2124$ & 3.1 & $7,800,000$ & 3.4 \\
\hline Cancer & $30 / 2102$ & 1.4 & $3,400,000$ & 1.2 \\
\hline Dental & $2 / 341$ & 0.6 & 88,000 & 0.3 \\
\hline Environment & $4 / 308$ & 1.3 & 576,000 & 1.6 \\
\hline Eye & $6 / 850$ & 0.7 & 547,000 & 0.6 \\
\hline General medicine & $10 / 3416$ & 0.4 & $1,285,000$ & 0.5 \\
\hline Child health & $131 / 1182$ & 11.1 & $21,817,000$ & 17.1 \\
\hline Heart/lung & $64 / 2000$ & 3.2 & $7,144,000$ & 2.5 \\
\hline Neurology & $18 / 362$ & 1.3 & $2,541,000$ & 1.7 \\
\hline Total pediatrics & $390 / 14,370$ & 2.7 & $52,700,000$ & 3.1 \\
\hline
\end{tabular}

Table 5. NIH research project support to US pediatric departments-1983*

\begin{tabular}{cccc}
$\begin{array}{c}\text { No. of grants } \\
\text { per department }\end{array}$ & $\begin{array}{c}\text { Total no. } \\
\text { of grants }\end{array}$ & $\begin{array}{c}\text { No. of } \\
\text { departments }\end{array}$ & $\begin{array}{c}\text { Average dollar } \\
\text { support/department }\end{array}$ \\
\hline 1. 85 & 85 & 1 & $\$ 14,006,000$ \\
2. 41 & 41 & 1 & $6,210,000$ \\
3. 36 & 36 & 1 & $5,640,000$ \\
4. $21-25$ & 45 & 2 & $3,325,000$ \\
5. $16-20$ & 58 & 3 & $2,225,000$ \\
6. $11-15$ & 78 & 6 & $1,555,000$ \\
7. $6-10$ & 127 & 16 & $1,311,000$ \\
8. $2-5$ & 81 & 24 & 442,000 \\
9. 1 & 21 & 21 & 136,000 \\
10. 0 & 0 & $45(38 \%)$ & 0 \\
& & & $81,964,000$ \\
Totals 4.8 & 572 & 120 & \\
\hline
\end{tabular}

* Top $14(12 \%)$ pediatric departments receive 343 or $60 \%$ of grants. Bottom 90 (75\%) pediatric departments receive 102 or $18 \%$ of grants.

14,370 total grants awarded. This comprises about $3 \%$ of the total NIH funds and $10 \%$ of the funds given to clinical departments.
The distribution of NIH funds to clinical departments is shown in Table 3. Departments of Medicine receive 17\% of NIH funds, making them the best supported clinical department by a considerable margin. Pediatric and surgical departments follow with about $3 \%$ of the total support.

The distribution of grants by each NIH Institute to pediatric departments is shown in Table 4. The National Institute of Child Health and Human Development is the largest source of funding for pediatric research $(\$ 22,000,000 / y r)$, but only $11 \%$ of their grants and $17.1 \%$ of their funds support pediatric research. This institute also provides considerable support for studies on maternal health and reproduction. The value of a clearly identified institute becomes apparent when the National Institute of Child Health and Human Development is compared to the National Eye Institute; $37 \%$ of National Eye Institute grants and $42 \%$ of National Eye Institute funding goes to clinical Ophthalmology Departments.

Several other institutes that contribute significantly to pediatric research include the National Heart and Lung Institute and the National Institutes of Arthritis, Digestive and Metabolic Disease (\$7.8 and $\$ 7.1$ million, respectively), followed by the National Institute of Allergy, Immunology, and Infectious Diseases (\$4.2 million) and the National Cancer Institute ( $\$ 3.8$ million).

Table 5 combines the Federal research project support to pediatric departments with that to individual children's hospitals. This increases the Federal support for pediatric research to $\$ 82,000,000$, because of the large research efforts of a few major pediatric hospitals (their research support is administered through the hospital, rather than the associated university). Three departments receive $162(28 \%)$ of the 572 total pediatric grants. The top 14 funded departments receive $343(60 \%)$ of the 572 pediatric grants. The average number of grants to each pediatric department is 4.8 , which amounts to an average of $\$ 688,000$ per department per year. Forty-five schools have no NIH pediatric support and another 45 have minimal research support (one to five grants). The bottom 90 schools ( $75 \%$ of the 120 schools) have 102 of the 572 grants or about $18 \%$ of the funds.

This top-heavy distribution of Federal support to a minority of pediatric departments is probably inevitable, and may be desirable by concentrating investigators in a few locations where they will form a critical mass and can share facilities and specialized personnel. On the other hand, most medical students will never have exposure to a nationally competitive pediatric investigator.

While the yearly support for pediatric research of $\$ 82,000,000$

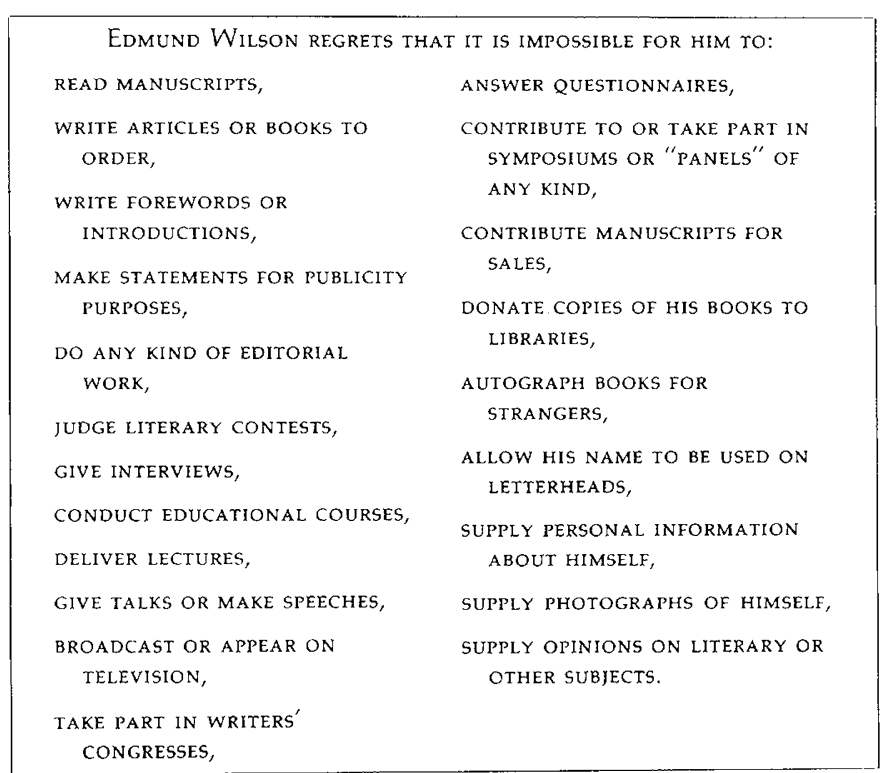

Fig. 1. Edmund Wilson's calling card. Reprinted with permission from Gill, Breadan Here at the New Yorker, Random House, New York 1975. 
Table 6. The ten commandments (for future pediatric researchers)

1. Do consider research-if in high school you liked to fix bikes, write poetry, or cook without a recipe, and got an A in algebra

2. Do try research in high school, college, or medical school but get a mentor for guidance and technology

3. Do take liberal arts in college; learn to write; use your imagination; avoid engineering

4. Do go to the best school/hospital/fellowship you can afford. Your peers are critical; do not worry about the weather

5. Do write a case report (or more) during medical school

6. Do not get a PhD

7. Do learn all about one subject

8. Do marry a spouse with a career or enough money that he/she will not bug you

9. Do develop inexpensive tastes: Princes over Rossignols, Schwinns over Mercedes, Levis over Guccis

10. Do choose a fellowship wisely; do not be the first, last, only, or one of 10 fellows; check the track record of the past fellows

is not an insignificant amount, it pales when compared to just a few items from the defense budget $(\$ 2.2$ billion for $120 \mathrm{~F} 16$ fighters, $\$ 1.4$ billion for four C-5 cargo planes) or to the VA Medical Research budget $(\$ 217,000,000)$ including $\$ 53,000,000$ for Agent Orange research. Thus the government spends three times more money on research relevant to the nation's veterans than research relevant to the nation's children.

\section{PEDIATRIC CAREER PASSAGES}

Despite these disadvantages, the obstacles to pediatric research are not insurmountable and, indeed, may offer the degree of adversity necessary to build character and persistence. Yet it is necessary to find the funds, time, and the location to conduct the research. This requires careful planning at every stage of one's career, preferably starting in high school, but in any case, the earlier the better.

Edmund Wilson, the author, had a calling card which he used to discourage all those that would interfere with his writing (Fig. 1). Investigators could use such a card. My own research (and I am sure that of others) has been interrupted by an endless array of natural disasters (earthquakes, ski accidents), family obligations (orthodontia appointments, children's tennis tournaments, cat's illnesses), society obligations (jury duty, commencements, receptions), but particularly my other professional duties. From these experiences I have identified some positive and negative factors facilitating a research career. These factors will vary at each stage of one's investigative career. I have labeled these career stages the initiation stage (for students, residents, and fellows), the establishment stage (for instructors and assistant professors), and the perpetuation stage (for associate and full professors).

\section{INITIATION STAGE}

The first suggestions (Table 6) are for the the potential researcher at the initiation stage. Many can do research who think they cannot and, unfortunately, vice versa. But medical students should give research a try. This is true particularly for students who like to repair things, write creatively, solve problems, and enjoy a challenge. An early experience (preferably in high school) in a research laboratory is an ideal opportunity to test the waters. Although a few geniuses can work alone with a home chemistry set, most will need an established laboratory and an experienced supervisor. An early mentor who can focus, direct, facilitate, and encourage is a key factor in the career of most scientists. A continued association with a mentor and his/her research laboratory throughout college and medical school is most desirable.

In college it is not essential to be immersed in science. In fact, the curriculum of a technical major (such as engineering) may be so crowded and demanding that there is little time to think creatively. It is my impression that a disproportionately high percentage of outstanding medical researchers have attended liberal arts colleges with majors in history, literature, or philosophy. These individuals, particularly those who went to a high priced, small college, have learned to write better than those who went to large universities; these writing skills are an enormous advantage to the potential investigator.

In medical school a research bent can be sharpened (and one's literary skills maintained) by writing one or more scientific papers. This can be a single case report with a review of the literature; faculty guidance is almost always available. A published paper is a strong indication of extraordinary drive that identifies the young author as possessing high potential.

Even though more research grants are being awarded to $\mathrm{PhD}$ scientists, I do not believe it is necessary for the MD to get a $\mathrm{PhD}$. Indeed 3-5 yr in serious research work at the postdoctoral level, augmented by selective course work, is a wiser investment in time than the often prolonged course work of the PhD. Nevertheless, the $\mathrm{PhD}$ researcher has one advantage over the $\mathrm{MD}$, in that he/she has a narrowly defined area of research expertise. By contrast, the pediatric investigator who has completed a fellowship has a broad spectrum of clinical and investigative knowledge and often is tempted to pursue several simultaneous research projects. This should be avoided since the beginning researcher's experience, technical help, and financial resources are limited.

One indispensible ingredient to research success is time. If married, a tolerant and supportive spouse who does not aspire to early financial success is critical. Since the typical male pediatric investigator may not have his first permanent position until age 35, a wife who wants an expensive house and expects to be wined and dined regularly will not be a good choice. Thus, the researcher needs to keep his or her tastes modest, and find excitement in finding enzyme defects, rather than underpriced stocks. A spouse with an independent career often can be understanding and supportive.

Perhaps the most important decision for the potential researcher is the choice of the right fellowship. Since trainees pick up most of their research style from their mentors, choosing the ideal mentor is crucial. A good mentor is usually a seasoned one who has a critical mass of other trainees, yet not so many that there is little opportunity for individual interaction. Many famous mentors are on the lecture circuit much of the time; this can quickly be determined by speaking to the present trainees.

Performing well in a nationally recognized fellowship program is much more important than prior academic credentials. Excellent credentials (eg, in college, medical school, and residency) will help procure a good fellowship, but from then on one's performance as a fellow determines future research opportunities.

Table 7. The ten commandments (for beginning pediatric researchers)

1. Do choose an institution that will help you, not one that needs you; stay downstream of the flow of knowledge

2. Do apply (and reapply) for grants

3. Do choose a research area unique to pediatrics

4. Do not take on enormous patient responsibilities; do maintain some

5. Do not start your own division

6. Do not write texts, reviews, case reports, teaching modules

7. Do not be housestaff supervisor or chair of the intern selection committee

8. Do live close to the laboratory

9. Do use new techniques on an old problem; do use old techniques on a new problem; do not use new techniques on a new problem

10. Do stick to a single problem 


\section{ESTABLISHMENT STAGE}

The second stage begins at the end of fellowship training, when the young scientist seeks his or her first academic position. My suggestions are summarized in Table 7. Assuming there are options, it is better to seek a position where one can continue to learn and grow academically, ie, a place that will further one's career. Beware of the situation so isolated or so thin that you are the expert in your field. Stay downstream of the flow of knowledge. That does not mean that one has to go to a prestigious or large institution, only that wherever one goes there should be the opportunity to learn. This may take the form of a single senior colleague or a single unique research resource. Like the Marines, one good man (or woman) is all that is needed.

The next step is to choose carefully an appropriate research focus. I suggest a pediatric focus, preferably disease or patient oriented. Although some pediatric researchers compete successfully with basic scientists in fundamental research, most cannot. The pediatric researcher should take advantage of the fact that he or she can know both pediatric medicine and fundamental science.

The next important thing to do is apply and reapply for research support. The discipline of writing grants is a useful one to master, and one might as well accept it as part of the research endeavor. The researcher will soon learn that the pain of a rejected grant is intense but short lived and not without some benefit. Remember that the proposal is not necessarily bad because it has been rejected (nor good because it is funded!), and that any proposal can be improved with a rewrite and resubmission.

One must carefully consider what role to assume in the pediatric department. The temptation to become the complete pediatrician must be avoided. There simply is insufficient time and too much information to be the whole pediatrician and the competitive researcher. Similarly it is tempting to provide clinical care to a large group of patients. Good clinical care is extremely demanding and leaves little time for in-depth research effort. On the opposite side of the coin, a complete retreat from patient responsibility may sound like a good idea and it may be for a few years. But longer term, why be an MD in a pediatric department if you do not do pediatrics? Indeed, senior members of your department may ask the same question at promotion time. Further, one's research will lose its unique pediatric focus. Perhaps the happy medium is a single clinic devoted to patients with the clinical problem you are working on, with a limited effort to maintain general pediatric skills through reading, grand rounds, and the usually necessary attending rotations on the general pediatric wards.

Department administration also can tempt the young researcher. First, avoid being the division chief. One person divisions, particularly new one person divisions, are perilous; there are no senior colleagues, minimal equipment, and no ongoing fellowship programs. Instead there is the need to develop a cadre of patients, personnel, and research program. Creating a division is a 2-yr job with research on the back burner.

Other administrative tasks such as housestaff supervisor, intern selection chair, and grand rounds coordinator are equally time consuming and research depriving. These are important jobs but without much payoff, particularly at promotion time. They are ideal for senior professors whose careers are established and whose research is waning. Offer to organize the pediatric picniconce!

A temptation of many young faculty is to fatten their bibliography with review articles, case reports, or patient series. Minimize these efforts, since they take enormous time, and distract from research. Books and teaching modules are worse. Even with a $10 \%$ royalty or a $\$ 500$ honorarium, the time spent comes to about $\$ 1.00$ per hour, less than the minimum legal wage.

Instead, focus on a single problem and stick with it. Granting agencies, promotion committees, and your peers are looking for
Table 8. The ten commandments (for established pediatric researchers)

1. Do go on sabbatical or study leave: but go to one place only

2. Do select your fellows on their potential, not on their alma maters

3. Do make your fellows better than you and then collaborate with them

4. Do go to scientific meetings, study sections, research conferences

5. Do not become a chairman, editor, president of a medical organization, or a roving visiting professor

6. Do learn new techniques, new technology; visit other laboratories

7. Do move if necessary to a better situation-do not worry about the weather

8. Do stay active in the laboratory-supervise a medical student if necessary

9. Do keep your research focussed; be the world's authority on one subject

10. Do not write case reports-you have already got tenure

someone who is an expert, can exploit past observations, and enlarge the field in a systematic fashion. This is a formidable accomplishment in a single area, and a near impossibility in several areas. Along that line, bring new techniques to an old problem. If you have a unique technique or method, you may want to apply it to a new area, particularly with the help of a collaborator in the new field. Avoid new techniques on a new problem - they take too long and probably will not work. Live close enough to the hospital so that you can go back to the laboratory at night and on weekends. Most good discoveries are made alone and at odd hours. Weekend work permits one to start 2- or 3-day experiments on Thursday and Friday.

In sum, work hard-your competitors are working hard too. But hard work brings success and success is satisfying. In the process, remember your family-they are also important and enjoyable. Do not neglect them.

\section{PERPETUATION STAGE}

Let us now turn to the perpetuation stage for associate or full professors. You are now a full-fledged member of the department with an established research record and some membership credentials (Society for Pediatric Research, American Pediatric Society, American Society for Clinical Investigation, NIH Study Section, etc.). You can now focus on a single large problem over a longer period of time, since the need for publications is past. You can now aim for significant contributions rather than prolific publications. Table 8 provides some suggestions for this career stage.

You may be offered a position at another institution, and this should be carefully considered. Most academicians move at least once in their career, and this provides new opportunities, new colleagues, and a chance to get out of some responsibilities that no longer are valuable. For one's family's sake, a move prior to your children entering high school is usually desirable.

You may be prime candidate for a chairmanship offer. Acceptance is usually a fatal blow to a research career. Very few pediatric chairman have been able to remain productive investigators. The few that do, do so, I believe, by 1) neglecting their duties as chair, 2) working constantly, 3) finding an associate who does the day-to-day work of the laboratory and is willing to remain in a subordinate position, or 4) all of the above. An alternative to accepting a Chair is to make an effort to remain productive in pediatric research, particularly since you have invested 10 yr or more attaining a position where you can readily manage your own research.

To remain productive in pediatric research is as difficult as achieving initial success. Several perils arise. Large administrative jobs, such as hospital chief of staff, medical school associate dean, or journal managing editor can be as demanding as a depart- 
Table 9. The ten commandments (for women pediatric researchers)

1. Do take high school auto mechanics, math, and physics-in that order

2. Do beware of those who say you are remarkable, when they mean you are remarkable for a woman

3. Do remember your liberated male peers are your competitorspaternalistic full professors may be your advocate

4. Do realize that the real rules of the academic game are not in the faculty handbook, but neither set applies to you

5. Do toss out all books on child rearing written for fulltime mothers

6. Do marry another doctor-he can take care of the sick child and you can go to work

7. Do marry someone who will help you and not need help in his career

8. Do work farther from home than your husband-he can go home for emergencies

9. Do not work alone; supervise others; develop a team

10. Do remember that the last stage of research is not discovery but presenting, writing, and receiving credit; avoid the Rosalind Franklin syndrome

mental chair. Excessive travel as a visiting professorship, postgraduate course faculty, and foundation board member interrupts research productivity. Time away from the laboratory is better spent at scientific meetings, research conferences, and study sections. The latter is a particularly valuable educational exercise. The opportunity to evaluate excellent grants can only improve your own grant-writing skills.

A period of time spent exclusively on research can usually be achieved only by going on sabbatical. A research experience in another laboratory will disconnect you from everyday distractions and provide an opportunity to learn new techniques and meet new colleagues. It is a chance for renewal and intellectual recharging.

Research is said to be a young person's game. This means, for the established investigator, choosing and working with bright young associates. Fellows should be selected on their potential, rather than on their past credentials. Excellent fellows come from both sexes, all ethnic groups, all countries, and all nationalities; your continued success will depend on attracting and selecting the best available talent.

\section{FOR WOMEN ONLY}

I now turn to some special advice for women who go into medicine (Table 9). Most women physicians have been on the fast academic track since high school. Very few young women can make a late decision to go into medicine, because she has probably not taken sufficient high school math and science for college premedical courses. By contrast, most bright high school males are automatically programmed into science, allowing them to switch readily to premedicine. The moral is that young women should take math and science in high school.

Newly graduated women physicians, in the eyes of their friends, parents, and themselves, have accomplished so much that they often do not aspire to become an emminent scholar in their field. Further, women do not play the academic mating game. There are few women in the "old boy's club" of senior professors at major research centers who recommend and watch out for their trainees and younger colleagues. To break into this network, it is wise to develop an association with one or more established colleagues in the department. Remember paternalistic full professors are much less likely to be threatened by a smart young woman than a competing assistant professor.

The triple role of mother, wife, and pediatric researcher is a special challenge. You will need a good baby sitter or housekeeper and a supportive husband; one who does not need taking care of, and instead will help take care of the children. A fellow pediatrician who can take care of the sick baby is a particularly good choice. You too, should live close to the lab, but further from home than your husband's work, so that he is the one who goes home for family emergencies, mid-day chauffering tasks, and daytime PTA meetings.

Academic women must resist the temptation to work alone, despite their upbringing of independence and self-reliance. They must depend on assistants and junior associates, realizing that they are the way to multiply her research efforts. They must be willing and able to supervise. Women must present, write, and receive credit for their research work. They must avoid the Rosalind Franklin ${ }^{3}$ syndrome.

Acknowledgments. The author is indebted to Drs. Ephraim Levin and Eric Elliot, General Clinic Research Centers Branch and Ms. Ruth Black, Division of Research Grants of the National Institutes of Health and Dr. Earl S. Freed of the Veterans Administration for providing statistical information, and to Ms. Winifred Cole for assistance with the manuscript.

\footnotetext{
${ }^{3}$ Rosalind Franklin was an $x$-ray crystallographer whose unheralded early work
} on DNA allowed Watson and Crick to formulate the structure of DNA (5).

\section{REFERENCES}

1. Fredrickson DC 1981 Biomedical research in the 1980s. New Engl J Med 304:509-517

2. American Academy of Pediatrics Committee on expanding pediatric careers: career in pediatrics, 1979. Pediatrics 64:259-269

3. Johnston RB Jr 1981 The impact of research in pediatrics on the health of children. Pediatr Res 15:1465-1467

4. Stiehm ER, DeVivo DC, Brann AW Jr, Fisher DA, Hodson WA, New MI Shearer WT, Sokol RJ, Sunshine P, Taeusch HW 1984 Advances in perinatology from the clinical research centers. Pediat Res 18:197-212

5. Sayre A 1975 Rosalind Franklin and DNA. New York, Norton 